\title{
INCLUSION ACROSS BORDERS: YOUNG IMMIGRANTS IN FRANCE AND ENGLAND
}

\author{
Oakleigh Welply ${ }^{1}$ \\ Durham University, United Kingdom
}

\begin{abstract}
Globalisation and migration have brought new challenges to education in the past decades, raising questions about how schools can promote inclusion within contexts of increased diversity (Vertovec, 2017). The concept of inclusive education itself remains contested, with different meanings across national contexts. This makes a comparative focus on inclusion particularly relevant to understanding different languages of inclusion and the ways in which these are articulated across national and institutional contexts. This article examines these challenges to inclusive education through a comparative lens, by looking at the identity narratives of children from immigrant backgrounds in primary schools in France and England. Drawing on data from a cross-national ethnographic study which investigated the experiences of thirty four 10 and 11 year old children of immigrants in two primary schools (one in France and one in England), this article looks closely at the narratives of four girls from immigrant background, to investigate the way they negotiated linguistic, ethnic, cultural and religious differences as part of their identities in school. The narratives of the four girls were selected as particularly relevant for thinking about the role of values, structures and children's own understanding in defining modes of inclusion and exclusion in school. This article explores the interplay between the girls' representations of school as an institution (formal spaces), their collective narratives of difference and Otherness (social imaginary in informal spaces) and their individual forms of positioning (identity narratives). This article shows how, despite contrasting approaches to inclusive education ("indifference to differences" in the French school and recognition of differences in the English school), the girls' experiences of inclusion/ exclusion presented strong points of convergence across countries. Their experiences were less dependent on school approaches to inclusion than on children's capacity to understand "contextual clues" (Gumperz and Roberts, 1990), implicit expectations from teachers and school values. This holds implications for thinking about mechanisms of inclusive education and their implementation across institutional contexts.
\end{abstract}

Keywords: globalisation; migration; inclusion; France; England; Ricoeur

${ }^{1}$ Correspondence: School of Education, Durham University, Leazes Road, Durham DH1 1TA, United Kingdom; Email: oakleigh.welply@durham.ac.uk 


\section{Introduction}

Globalisation and migration have brought new challenges to education in the past decades, raising questions about how schools can promote inclusion within contexts of increased diversity (Vertovec, 2017). The concept of inclusive education itself remains contested, with different meanings across national contexts. Inclusion can be interpreted in multiple ways and varies across educational contexts. Initially associated with removing barriers to the education of children/students with disabilities, the concept of inclusion has, in recent years, widened to the idea of ensuring all young people get to participate in school, without any discrimination based on disability, race, ethnicity, language, religion, gender or sexuality (Gosh and Galczynski, 2014; Armstrong et al, 2016). This variety in understandings and focus of inclusion means that the concept itself is ambiguous and susceptible to different, sometimes contradictory, definitions. As argued by Slee, there are multiple "languages of inclusion" which might vary across educational landscapes and national educational systems (Slee, 2009, p.178). This makes a comparative perspective on inclusion particularly pertinent, as much can be learned by looking at the ways in which inclusion is articulated within specific national contexts. In recent years, studies on inclusion and education have increasingly focused on inclusion as a response to migration. Namely, how can educational systems, often strongly embedded in national, monolingual and monocultural values and curricula, be inclusive of all children regardless of their immigrant, racial, ethnic, linguistic or religious background? Central to this question are the ways in which schools can promote spaces in which Otherness is not perceived in a negative manner but is integrated within holistic educational approaches (school ethos, curriculum, pedagogy).

This shift in focus has been framed by global policy, media discourse, and national educational policy. It stresses the importance of a multi-levelled approach to understanding issues linked to inclusion and migration (Welply, 2019). Global policy, such as Education for All (2000), the Millennium Development Goals (2000-2015) and more recently the Sustainable Development Goals (2015-2030) have all brought to the fore the need for inclusion of all children in contexts of increased migration and diversity (Miles and Singal, 2010; Fukuda-Parr, 2016). One of the central goals of these policies has been to provide access to education for children from minoritized groups who would suffer from multiple barriers in terms of ethnic and linguistic background, gender or poverty, to name a few. Whilst earlier policies tended to promote a rather narrow definition of inclusion in these contexts, understood as access or enrolment only, the recent SDGs and associated initiatives have widened and deepened the understanding of inclusion as quality of education beyond access and support throughout people's learning life (Unterhalter, 2014; Aikman and Dyer, 2012).

These global goals are not always that easy to implement at a national level, where educational systems and pedagogical approaches are shaped by values, practices, and institutional structures at a local level. Conceptual constructions of difference and Otherness, and their place in the public sphere of school, will vary greatly across national contexts. Ideas of inclusion are shaped by beliefs and values about the place of difference in society (Alexander, 2000). These in turn shape discourses, structures and conceptual constructions of Otherness which permeate educational systems, institutions and school practices (Welply, 2019).

This makes a comparative focus on inclusion particularly relevant to understanding different languages of inclusion and the ways in which these are articulated across national and institutional contexts. This article examines these challenges to inclusive education through a comparative lens, by looking at the identity narratives of four girls from immigrant backgrounds in primary schools in France and England. Based on a larger study which comprised 34 children, this article focuses particularly on four girls and their narratives which were considered particularly relevant for thinking about 
the role of values, structures and children's own understanding, and examine modes of inclusion and exclusion in school. It investigates the way the four girls negotiated linguistic, ethnic, cultural and religious differences as part of their identity narratives in relation to school. Their narratives were located at the interplay between their representations of school as an institution (formal spaces), their collective narratives of difference and Otherness (social imaginary in informal spaces) and their individual forms of positioning (identity narratives).

This article shows how, despite contrasting approaches to inclusion ("indifference to differences" in the French school and recognition of differences in the English school), the girls' experiences of inclusion/ exclusion presented strong points of convergence across countries. Their narratives showed that their experiences of inclusion of Otherness within different school spaces were less dependent on school approaches to inclusion than on the girls' capacity to understand "contextual clues" (Gumperz, 1982), implicit expectations from teachers and school values. This holds implications for thinking about mechanisms of inclusive education and their implementation across institutional contexts.

\section{Inclusion, migration and education in France and England}

France and England offer interesting contexts for reflecting on different approaches towards inclusion for young migrants and the way they are articulated in practice in school. At the core of these differences lie contrasting approaches to equality and what it means to offer equal education to all. In England, the approach to inclusive education is closely associated to mainstreaming and builds on the idea that all children should have equal access to quality education and equal opportunities to benefit from it (Mintz and Wyse, 2015). This entails the recognition of "difference", whether it be disability, linguistic, gender, ethnic or religious particularities (Raveaud, 2006). Whilst inclusion in England initially focused mainly on children with disabilities or special educational needs, the concept has now widened to include all children, in contexts of migration and linguistic diversity (Tomlinson, 2015).

Schools have a duty to provide the necessary support and resources to allow children to benefit from the educational system provided. This involves a differentiated approach to learning, to meet the various needs of children, including (in principle) targeted linguistic support for newly arrived children. In the context of migrant children, this could entail language support, a "celebration" of diversity (cultural, ethnic, religious) or specifically adapted curricula and/or assessment (Liu et al, 2017). This approach to inclusion, closely aligned to a multicultural approach to education, has been criticised from different perspectives. On the one hand, it has been accused of creating separatism, communitarianism or at its worse, extremism (Morgan, 2015). On the other hand, it has been critiqued for failing to promote inclusion beyond a superficial approach, which does not provide adequate support and resources for the children who need them and hides a more assimilationist monocultural approach towards minoritized children ${ }^{2}$ (Gillborn, 2015).

This approach reflects a neoliberal shift in educational policies, in which a state driven inclusive educational approach has been replaced by a more individualised one, where the responsibility rests with the family and communities to "integrate" (Warmington et al, 2018). In terms of inclusion for newly-arrived migrants, or children with English as an Additional language, this means that there is no separate instruction. Teachers and bilingual support assistants (when available) hold the responsibility for

\footnotetext{
2 The term "minoritized" here refers to the terminology used by David Gillborn, to draw. "attention to the social processes by which particular groups are defined as lesser or outside the mainstream" (Gillborn, 2010: 273).
} 
meeting the needs of migrant children. Previous funding to support ethnic minority pupils (Ethnic Minority Achievement Grant) was discontinued in 2011. Since then there has been no ringfenced funding for ethnic minority children in schools. Funding for ethnic minority pupils is now part of general school funding and follows the national funding formula for schools (NFF). This has had a mixed impact on the amount of funding allocated to ethnic minority children in schools (Hutchinson, 2018).

The French approach to inclusion for young migrants stands in sharp contrast to the English model. The French educational system aims to promote inclusion by promoting a French Republican model of "egalitarianism", which seeks to remove all specificities (ethnic, linguistic, religious) from their "pupil-citizens" to ensure that everyone receives the same education, regardless of particularities. This approach makes it difficult to develop differentiated learning in the classroom (Raveaud, 2004). Inclusive education is a fairly new focus in France, where a tendency towards separate classes or institutions has tended to dominate until the early 2000s (Plaisance and Schneider, 2013), influenced by academic work from anglophone countries (US, UK, Australia, NewZealand).

Despite a shift towards a more inclusive approach, recent reports have highlighted the inadequacy of provisions for students with disabilities or special educational needs (Toubon et Avenard, 2018). Regarding young migrants, the values promoted by the French Republican model emphasise a unitary French culture and language, which encourages an approach based on "indifferences to differences" in school (van Zanten, 1997; Raveaud, 2003; Meer et al., 2009:414). This means that linguistic, religious or cultural differences are not taken into account and often constructed as undesirable in the public school sphere (Welply, 2017). Newly-arrived children and children with interrupted school trajectories (as a result of migration or belonging to the traveller community) are put in separate instruction classes for the first year of their schooling in the French system, with a progressive evolution towards mainstreaming (Delamotte, Penloup, \& Reuter, 2016). Similarly to the English model of inclusion, the French approach has been criticised for being out of date and failing to deal with the new diversity (linguistic, ethnic, religious) in society. Debates around laïcité (secularism) in schools which have crystallised around the interdiction for Muslim girls to wear headscarves in school has created strong rifts in political and academic communities (Meer et al, 2009).

England and France thus present strong contrasts in their understanding and approach to inclusion in schools. These are underpinned by different conceptual constructions of difference (Welply, 2019). In England, inclusive education emphasises differentiation, as a way of including children from immigrant backgrounds, whether it is through language support, celebration of diversity (religious festivals, a variety of texts and focus in the curriculum). In France, inclusive education emphasises normalisation as a way of ensuring everyone is assimilated within the Ecole de la République. These reveal different understandings of equality, with on the one hand an English version of "equality of opportunity" and on the other hand a French version of "equality of treatment" (Raveaud, 2006).

Despite these differences, both school systems' approach to inclusion have been criticised for not actually promoting inclusive practices for immigrant background children. Both systems have been critiqued for maintaining ethnocentric and monocultural curricula, educational practices and structures (Gillborn, 2015; Lorcerie, 2011).The linguistic needs of migrant children are most often not met, and multilingualism tend to be viewed along a deficit model as preventing children's linguistic and cognitive development (Cusset et al, 2015; Liu et al, 2017).

Research on migrant children's experiences in schools also present points of convergence between France and England. In both countries, children report feeling their Otherness is illegitimate in formal school spaces and the need to either adapt to dominant 
monocultural school values or stand in opposition to them (Youdell, 2003; Lorcerie, 2011). Whilst there is not the space to cover all areas here, in both countries, studies have shown how migrant children's experiences are constructed in relation to discrimination (overt and tacit) and stereotyping, both by teachers and peers. Stereotypes vary across ethnic, linguistic and religious groups, as well as by gender (Youdell, 2003; Shain, 2012; Lorcerie, 2011) and impacts on children's experiences and identities. These exclusionary mechanisms work against many of the principles of inclusion promoted by schools.

The above shows the ways in which inclusion can take on different forms and conceptualisations in different national educational contexts. This will lead to different practices of inclusion in schools and the classroom, and different experiences for children from immigrant backgrounds. Moreover, the principles of inclusion do not always get translated in practice. Institutional constraints, values and attitudes in the classroom all participate in forming environments that will foster or hinder inclusion. This article examines these challenges to inclusive education through a comparative lens, by looking at the identity narratives of four girls from immigrant backgrounds in primary schools in France and England. It is premised on the assumption that the perceptions of younger children can greatly contribute to discussions around inclusion and education (Katz, 2004). Children's experiences are not limited to the immediate, micro-level but are inscribed within wider socio-cultural experiences (Ansell, 2009). As such, listening to their voices and examining their narratives around identity, Otherness, inclusion and belonging can shed light on wider issues associated to inclusion, migration and education.

Theoretically, the notion of narrative in this paper is underpinned by Ricoeur's concept of narrative identity and the dialectic between idem (permanence) and ipse (change) (Ricoeur, 1992; Welply, 2015). This dialectic, which involves an ongoing process of self-constancy and self-rectification, recognises the dynamic character of identity, as an act of reinterpretation of the stories we tell ourselves over time (diachronic and synchronic) and across different spaces (Ricoeur, 1992; Kearney, 2004). From this perspective, identity narratives are not solely an individual act of self-definition but are affirmed through others and with reference to wider symbolic and imaginary representations (for example: school, society, what it means to belong).

Thus, in this paper the narratives presented here, although restricted to four children, are inscribed within wider collective narratives and social imaginaries in the school, as well as in the institutional symbols and representations (Ricoeur, 1992). However, findings in this article also highlight the limitations of Ricoeur's narrative identity in acknowledging the role of "spaces" in which children's narratives develop, and the ways in which they are shaped by dominant values of the institution in which they are inscribed. To address this, additional theoretical concepts were integrated to the analysis, from the areas of sociology and sociolinguistics: Bourdieu's notions of symbolic power, legitimation and recognition, which were helpful in understanding the way children interpreted and navigated institutional values in their narratives; and Gumpertz's concept of "contextualisation cues" (1982).

\section{Formal and informal school spaces}

The concept of 'spaces' in this article carries both a material and a symbolic meaning. On the one hand, the material dimension of school spaces encompasses the different physical spaces within school such as classrooms, the school building, the playground. These spaces are all part of children's social and academic experiences in school. On the other hand, the symbolic dimension of school spaces refers to children's representations projected onto different school environments, as well as their social interactions in different areas of school. These symbolic dimensions of school space can be distinguished as formal and informal. Formal spaces include classrooms and places for whole school gatherings, such as halls, in which activities are organised and structured 
by teachers, as well as interactions with adults in the school. Informal spaces include spaces such as the playground and lunch halls, in which children are supervised but in charge of their own activities.

These informal spaces offer the opportunity for informal, non-teacher-led activities and interactions. They represent the "in-between" spaces of school (Lucey and Reay, 2000) as well as unsupervised interactions with peers. This distinction between formal and informal spaces is not static, nor does it represent fixed categories. These spaces took on different forms across the different French and English national school contexts, with different levels of separation between "formal" and "informal" in the English and the French school. This distinction also varied in the four girls' representations and understandings. Thus, in this article, references to formal and informal school spaces echo the representations of the girls' themselves. In their views, the boundaries between formal and informal spaces tended to be fluid, inscribed within both material and symbolic representations, as well as in the immediacy of interactions with teachers and peers.

Considering the above, and building on the girls' narratives, for analytical purposes this article distinguishes between formal school spaces (school as an official institution) and informal spaces (school as peers). However, it is acknowledged that these spaces are not clearly bounded but could intersect and overlap in the girls' representations. The use of "spaces" in the plural recognises the diversity of children's views and experiences.

\section{Immigrant-background: definition of terms}

The term 'immigrant-background' was selected to refer to the children who participated in this research. This choice of term was motivated by the distinction between "immigrant children" understood as children born outside of the country they live in, and "ethnic minority" which would refer to children who were born inside or outside of the country they currently live in, but which excluded children from White migrant backgrounds (e.g. from Eastern Europe). This choice of term was also motivated by a desire to overcome the conceptual gap between "ethnic minority" in England and "immigrant origin" (issu de l'immigration) in France found in academic literature in both countries .

The use of the term "immigrant-background" in this article refers to children who would be considered "second-generation immigrants". It includes children who speak a different language at home; whose parents experienced immigration as young adults and experienced a different educational schooling system. This term differentiates between "immigrant-background" children and "newly-arrived" migrant children, who would have a different experience of migration. Although the wider research reported here did include children from White migrant backgrounds (Eastern European countries), this article specifically focuses on children from postcolonial immigrant-backgrounds (Bangladesh for England, India and Hmong for France). The term was preferred over "secondgeneration", which can be considered problematic in that it creates categories and generations around migration that do not always reflect the experiences of immigrant families (De Rudder, 1998; Lorcerie, 2011).

Any use of terms carries its limitations, and the use of the term "immigrantbackground" is no exception, as it might exclude other aspects of children's experiences and identity. As such, in this article, this term functions as an initial analytical category to examine the experiences of inclusion of children from different linguistic, religious and cultural backgrounds. This article does acknowledge, however, that such a term does not fully encompass the complex and changing identities of the children participants, which tended to transcend set categories and labels. The term "immigrant-background" is thus 
used as a starting point, which recognises the socially constructed and fluid nature of these categories.

\section{Methodology}

The four identity narratives presented in this article are based on findings from an ethnographic study with primary children (10 and 11 years old) in two primary schools, one in England and one in France. The larger study comprised 34 children, but this article focuses on four girls, whose narratives were chosen as particularly relevant for thinking about the role of values, structures and children's own understanding in defining modes of inclusion and exclusion in school. The four girls were from immigrant-backgrounds. Although the paper adopts a comparative focus, the decision was made not to try to match children by national background, ethnicity, language or religion. This choice was motivated by the fact that the girls' narratives presented complex and fluid identities that went against categorising them along fixed external dimensions. Given the different composition of migrant backgrounds in France and England, it made little sense to try to match children "like with like" in terms of background. Thus, the narratives presented in this article offer an understanding of the ways in which the four girls interpreted the values of inclusion of the school and navigated them with their own resources. Details about each participant are given in the findings section, below.

The wider study included an equal number of boy and girl participants. Whilst including participants from both genders would have undoubtedly offered insights into gender differences regarding mechanisms of inclusion and exclusion at school, for the purpose of this article, the choice was made to focus on girls only. The role of gender is nevertheless recognised in this article. The choice of focusing on the narratives of girls gives a particular gender perspective on mechanisms of inclusion and exclusion in schools.

Given the nature of the research, which aimed to examine children's identities in different national educational contexts, the choice was made to spend extended time in each school (six months in the French school, four months in the English school) to develop close relationships with the children and allow them to become familiar with the researcher and the research process. The researcher followed one class full-time in each school, collecting extensive fieldnotes in and out of the classroom and engaging in informal conversations with children. Interviews were carried out with the children, first as groups to allow more ease during the process, and then individual interviews with a few children. All participants were fluent in English or French. Particular attention was paid to the inclusivity of the interview process for all children.

Interviews were designed to be age appropriate and great attention was given to the language and concepts used as well as to ethical issues. Children were made aware of the implications of sharing information with other children in the group, and the researcher ensured that children were not upset by some of the issues raised during discussions. Because of the length of the research project and the ongoing presence of the researcher, a good rapport was established with children prior to interviews, which allowed them to feel at ease during discussions and minimise the power differential between researcher and participants (Groundwater-Smith, Docket and Bottrell 2015). Activities during the interviews (role play, maps of the world, name tags) made the process more interactive and helped include the quieter children.

In addition to interviews, children were given diaries over a period of two weeks that they could choose to write or draw in. The general guidance was to write about themselves and their experiences of school. All interviews were audio-recorded and fully transcribed. Diaries were scanned and returned to the children. Transcripts, diary entries and observations were analysed following a thematic approach. Analysis started with immersion in the data in order to develop a general sense of what children had said. Data 
was then organised into wide themes, with a progressive focus on more specific themes and sub-themes, identifying patterns and critical events or utterances. This last step was achieved by relying on the more formal approach to thematic coding, based on Strauss and Corbin's method of 'constant comparison' (1998). Themes emerged from the data, guided by the research questions and the theoretical underpinnings of this study.

Data from field notes, diaries and transcripts were broken into small units (a sentence, paragraph, or speaker's utterance). The use of a systematic, sequential, and verifiable approach to data analysis ensured that the same procedure was used for each national case and provided a trail of evidence to help guarantee rigour, validity and reliability in the analysis.

In this process, analysis followed an iterative process, returning to different stages of analysis in a cyclical manner. Initially themes were developed within each school and then developed across schools. Nvivo was used to facilitate this thematic coding process. Overall, the analysis elicited 20 main themes and between 80 to 90 sub-themes for each school. This article focuses on the three main themes of identity, Otherness and feelings of inclusion/belonging in school and how these were developed in the four girls' narratives. These three themes were intertwined in the girls' narratives, which could be identified along two main axes: (I) Negotiation of Otherness across different school spaces and (II) Uncertainty and ambivalence around Otherness and belonging in school. These narratives are examined in the section "children's views".

\section{Schools' contexts of inclusion}

Both schools were situated in socially-disadvantaged areas of medium-sized towns, with a high proportion of immigrant families. The English school had a total of 384 pupils, whilst the French school counted only 181 pupils. Both schools had a significant proportion of children from immigrant backgrounds, although the different approaches to collecting and monitoring data on ethnicity in France and England made it difficult to gather comparable information. In the English school, most children from immigrant backgrounds were from Bangladeshi (14\%) and Polish (8\%) backgrounds. In the English school, the proportion of pupils with English as an additional language and of minority ethnic heritage was above the national average. In the French school, most immigrant-background children were from North African (15\%), South East Asian (13\%) and Turkish (8\%) backgrounds (Hmong, Laossian, Cambodian). There were no teachers from ethnic-minority groups in the French school, but there was one Bangladeshi and one Polish teaching assistant in the English school.

The two selected schools could be seen as somewhat typical of the overall value orientations towards inclusion in France and England (Alexander, 2000). The English school promoted a strong inclusive, multilingual and multicultural ethos and had been selected as a model school for the inclusion of children from immigrant backgrounds. Disabled children and children with special educational needs were included within mainstream schooling, with the support of allocated teaching assistants. The school celebrated diversity in different forms: through religious celebrations, multilingual displays across the school and the support of a bilingual coordinator and two bilingual teaching assistants. The French school was a strong illustration of the "indifference to differences" Republican principle, with no acknowledgement of children's cultural or linguistic backgrounds and very little knowledge of diversity in the classroom. Children with disabilities or special educational needs were instructed in a separate class, which ranged from age 6 to age 12, staffed with an untrained newly-qualified teacher. Speaking about children's religion in school was discouraged and a new school rule was passed during the time of observation to prevent children speaking another language than French during playtime, because of the risk of them using it to say insults that teachers or peers could not understand. 


\section{Children's views}

Two main narratives were identified from the four girl participants: (I) Negotiation of Otherness across different school spaces; (II) Uncertainty and ambivalence around Otherness and belonging in school.

\section{Negotiation of Otherness across different school spaces: the narratives of Marine and Taahira}

The identity narratives of Marine and Taahira, presented below, demonstrated a good understanding of the expectations around Otherness in their respective schools, as well as the ways in which these varied across school spaces. This enabled the two girls to adopt different identities that "fitted in" with the different school spaces. It shows how an understanding of the symbolic distinction between public and private spheres helped the young girls make decisions about how to negotiate their perceived Otherness and build fluid and changing identities.

\section{Marine, French school: negotiating Otherness across public and private spheres}

Marine was an 11-year old girl from a Hmong family which had emigrated to France. She was born in France and her parents had emigrated as teenagers. Her father was a factory worker whilst her mother stayed at home. Marine was the youngest child in a large family (four siblings) and had an extended family of uncles, aunts and cousins living in the same area. She was a high-achieving student and positioned centrally in peer group relations, with many close friends, girls and boys. Marine perceived herself as a good student, who had once struggled, but now clearly understood both the expectations of schoolwork and the role of school for future life. She considered herself to be quite a different person outside and inside the classroom, where she tried to be quiet and not get noticed.

Marine's identity narrative showed that her identity articulated together the "indifference to differences" approach in the French school and a strong attachment to her Hmong identity. She managed to negotiate what might seem at first as conflicting identity dimensions in a French school setting by positioning herself differently in different spaces and developing different narratives of Otherness in public and private school spheres.

Her awareness and capacity to adapt her identity in different school spaces and according to different expectations was demonstrated in the way she articulated home or family values with school values. Her Hmong family and identity were put forward as a reason for working hard in school. This built on a diasporic and transnational identity and feelings of solidarity towards the wider Hmong population, which, for her, justified working hard at school to earn money that could be sent to help the poorest Hmong people in Laos (for further discussion see also Welply, 2015; Welply, 2019). This is well illustrated by the interview extract below:

Marine: well, they are very poor over there [Hmong people in Laos] (...) for example, my cousins $(. .$.$) they go to school, to try to work, so they can$ then bring back money over there [to the Hmong people in Laos].

Underpinning this articulation of school and family values, was a separation between what legitimately belonged to the "home" or private sphere and what belonged to the "school" or public sphere. This included her name, as she only wanted to use her Hmong name at home, and her French name at school. She also demonstrated a good understanding of her fluid identities, which stretched across language-scapes: 
Marine: It's strange because with my cousins, I speak Hmong and French, whereas at school, I speak only French. I feel different.

Her narrative shows the ways in which she adopted different identity positions in different spheres and with different people, in different languages. Her negotiation of Otherness in school was also informed by her understanding of a distinction between formal and informal spaces in school. In formal school spaces, she tended to minimise her Hmong identity, and restrict it to what was acceptable in a context of "indifference to differences" and an emphasis on being a pupil rather than a whole child. As such, she only mentioned aspects of her Hmong identity that she deemed to be pedagogically legitimate in the context of the French school (Welply, 2017). In contrast, in more informal school spaces, Marine was much more likely to express elements of Otherness as part of her identity. This led to exchanges and discussions with peers, and forms of joint-cultural creation. (details of these have been examined elsewhere, for further discussion, see Welply, 2015). Other forms of intercultural exchange involved more day-to-day conversations, such as clarifying misconceptions and stereotypes about her Hmong background and the notion of "Asians" often used generally in France or explaining about Hmong people to friends. She complained, for example, about being labelled Chinese and finding this insulting.

Marine's understanding of the different norms and expectations around the place of Otherness within different school spaces (formal and informal) allowed her to negotiate her identity accordingly, by articulating official school values with peers' social imaginaries of Otherness. In this way, she was able to adapt to different values in different spaces, in ways that allowed her to legitimise her Otherness.

However, although Marine appeared to negotiate Otherness comfortably across different school spaces, this was not devoid of tension. Marine's identity narrative revealed the difficulty in negotiating conflicting values between what she perceived as tradition (home, family) and modernity (school, peers). She struggled to find a balance between what she saw as her families' wish to preserve Hmong culture and being able to adapt to life in France. In particular, she found the resistance of her family to mixed-ethnic relationships or marriages and their fear of losing linguistic and cultural identity difficult to reconcile with her desires and aspirations as a young girl.

Marine: It is important to continue to speak Hmong, because if we do not speak it, we will not be able to learn, and after a while... well Hmongs will stop existing, there will be nothing left. That's why our parents and our grandparents they absolutely want us to get married only with Hmong people.

Interviewer: how do you feel about that?

Marine: Well, maybe it's good to do that, to keep the Hmongs and everything, but it creates a lot of issues (...) forced marriages, sometimes hidden marriages...(...) older people they say if they marry they might stop speaking Hmong (...) if they get married to French people, then they need to integrate

The above shows some of the tensions that Marine felt in relation to cultural backgrounds that she perceived as at times mismatched or in opposition with each other. The last comment about the need to "integrate" also points to the particular assimilationist approach to inclusion in France and in French schools and the limitations of the "indifference to differences" model. 
The erasing of Otherness in the context of French schools seemed to make the inclusion of multiple identities more strained, even for a child such as Marine who understood different expectations and what values were legitimate in particular spheres/spaces. It helps understand the way Marine tended to try to keep different aspects of her identities separate, but also the way she tried to turn her Hmong identity into something more "pedagogical" to legitimise it in the school sphere. Here, Marine's identity narrative is underpinned by a dialectic between permanence (idem) and change (ipse) (Ricoeur, 1992), reflected by a tension between tradition (home, family) and modernity (school, French society). It could be that the assimilationist approach to inclusion in the French school did not allow her to find ways of bridging these tensions, thus leading to further polarisation between them. However, the strict separation between the public and the private in French schools also afforded her different forms of negotiation that might not have been available elsewise or elsewhere.

The above highlights the tension experienced by Marine in negotiating her Hmong identity with everyday life in France. This tension between the expectations and traditions of Hmong culture and the daily practices and relationships characteristic of youth culture in France reflect wider tensions associated with acculturation in a society dominated by monocultural values (Lorcerie, 2011). However, in Marine's narrative, this fear of losing Hmong identity through integration was located outside school, within the realm of the family and the community. In contrast, in her narrative, school represented a space in which her Hmong identity could be expressed rather than silenced in the name of 'integration'. In formal school spaces, this identity affirmation built on pedagogical, learning-oriented values, whilst in the informal spaces it took on more inventive forms of exchange, such as the joint-cultural creation she developed through singing with friends. In this sense, in Marine's narrative, school constituted a space in which she could overcome the tensions between integration/acculturation and fear of loss of Hmong identity.

This navigating between contrasting values and expectations in different spaces and spheres was also expressed in Taahira's narrative yet articulated differently.

\section{Taahira: separating the academic and the personal}

Taahira was an 11-year old girl born in England, with parents from Bangladesh. Her father had emigrated as a young child and her mother as a young adult to marry her father. Her father was a taxi driver and her mother did not work. Taahira was the oldest of a family of three. She was a good student, in upper sets in both English and Maths. She had two good friends, both from Bangladeshi families.

Similarly to Marine, Taahira's narrative expressed a tension between tradition and modernity, portrayed as an opposition between family values and school or peer values. This led sometimes to contrasting depictions of herself, depending on who the audience was. A stark example is found below in the way she described herself as a pupil:

(1) Interviewer: Taahira, how would you describe yourself as a pupil? Taahira: A punk

Interviewer: A punk. Really, do you behave like a punk?

Taahira: Yeah, I do graffiti, I did it all over my granny's...back garden. (Group interview)

(2) Interviewer: And what kind of a pupil are you?

Taahira: Errrr, I'm a bit shy...yeah, I don't talk much. 


\section{(Individual interview)}

Through these two contrasting comments, Taahira constructed a contradictory identity narrative. The 'punk' comment positions her as subversive, illicit and anti-rules outside school, whilst her other description positions her as a compliant and quiet pupil. Although Taahira's self-description as a punk is made jokingly, the illicit dimension conveyed by that comment reflects other comments made by peers about Taahira getting in trouble in the playground. Furthermore, it is inscribed in forms of popular youth culture, which Taahira perceives as conflicting with a positive pupil identity (see later section). Finally, Taahira introduced a shock effect through the contrast between her appearance (she only wore school uniform coloured clothes, even though this was optional, and always wore a headscarf) and the image summoned by the term 'punk'. The reaction of other children during the group interview and comments they made to me later stressed the effect of the strong contrast between affirmed and perceived identities (Welply, 2019).

Taahira's self-description as a quiet and shy pupil in the classroom reflects teacher stereotypes about Asian pupils (Mirza, 2015; Meetoo, 2019). Indeed, during class time, the teacher criticised her for not participating in discussions. In this light Taahira's 'punk' comment could be a way of distancing herself from this stereotypical compliant image of a pupil by adopting a more subversive identity narrative in front of her peers.

The contrast between Taahira's two comments reflects the dialectic between idem and ipse (Ricoeur, 1992). The idem dimension of her identity is characterised by her selfdescription as a shy and reserved pupil, which corresponds to the way she was generally perceived by teachers. Conversely, her 'punk' comment symbolises an alternative form of identity, through a process of self-redefinition, and points to the fluid and changing ipse dimensions of identity (Ricoeur, 1992).

Similarly to Marine, the way Taahira negotiated Otherness in school was built on a symbolic separation between public and private spheres. This involved recognising spaces in which Otherness was perceived as legitimate in school, such as Religious Education (R.E.), where she felt she could speak about Islam which was a strong part of her identity. However, she also was quite clear that she did not speak of religion with nonMuslim peers and felt that different religions were a basis for different friendships in school (see Welply, 2017 and 2018). Her religious identity in school was thus restricted to what she perceived as the legitimate curriculum area, R.E. or to alternative educational spaces such as Qur'anic school. This raises questions about approaches to inclusion in school and the way they did not always bring the desired effects.

For Taahira, the celebration of differences, such as learning about other religions or celebrating Eid, was something that helped her develop a separate identity rather than exchange with peers. As such, she perceived the existence of a "non-Muslim" public school sphere in opposition to her own private religious identity. She commented that she thought she was the only person in the whole school to wear a headscarf. Despite evidence of the contrary, this shows how Taahira viewed herself as a minority in a non-Muslim school. She established a similar distinction around the use of other languages. For her, speaking Bengali at school was only acceptable if it was "private" and could lead to problems or misunderstanding with non-Bengali speaking peers. This stood in stark contrast to the inclusive multicultural and multilingual policy of the school, with many multilingual signs and an emphasis on the celebration of different religions, languages and cultures.

However, in a similar way to Marine, Taahira did seek to legitimise Otherness as a form of learning in school, as shown below:

Taahira: I didn't know how to read Bengali numbers and stuff and there is now in the classroom $(. .$.$) we have these Bengali things, and like they have$ 
Bengali numbers, and they had to pronounce them in Year 5, and I learnt from that and the days of the week.

(Individual interview)

This view can be seen to confer educational and curricular legitimacy to Bengali in school. Tahiraa's articulation of Bengali as part of her identity was mainly located outside school in her family or the wider Bangladeshi community. She stressed the importance of being able to communicate with her family when she went to Bangladesh and mentioned that her cousin could not speak a word of Bengali, which she saw as a loss of identity. Like Marine, in Taahira's representation, the loss of language symbolised a loss of identity and connection with Bangladesh. This points to similar constructions of language and identity to those of Marine, and similar tensions inscribed within processes of acculturation in monolingual and monocultural societies (Welply, 2017).

Finally, Taahira mentioned experiences of discrimination and racism that she received from others. This included religious and ethnic discrimination with people teasing her about her headscarf, being called an 'Indian curry', and people making fun of Bengali men wearing 'skirts'. Forms of implicit discrimination from peers, which Taahira tended to internalise at times also illustrate the tension she experienced in negotiating Otherness in school (for further discussions of these mechanisms, see Welply, 2018). These forms of discrimination and stereotyping, combined with the implicit monocultural ideology of the school, could explain the fact that Taahira's identity narrative situated Otherness as confined to the private sphere in accordance with the specific expectations of the different school spaces, despite the strong inclusive and multicultural ethos of the school.

Taahira's identity narrative also carried points of tensions. These tensions were particularly salient in the conflicting values that underpinned her self-definition as a pupil as shown by her comment about 'not being a good pupil'.

Interviewer: What kind of pupils would you say you are?

Taahira: Not a good pupil, because if you were a good pupil, you wouldn't really watch stuff like East Enders or listen to music all the time.

(Individual interview)

This comment constructs elements of youth culture as opposed to a 'good pupil' identity. Taahira defines herself as not being a good pupil because she watches East Enders and listens to pop music. This opposition is a based on a tension between modern youth culture values and family values. This is symbolised by the contrast she draws between one of her friends Nabeela (also from a Bangladeshi family): She opposes, Nabeela's 'cool' mother who listens to music and her own 'freshie' mother, who cannot be friends with each other because of these differences.

Taahira: And our mum's are friends [hers and another friend from a Bangladeshi family], but not Nabeela's mum cause Nabeela's mum is a bit like cool, and she listens to music all the time and stuff.

Interviewer: Ah, really?

Taahira: Compared to us cause our mums are like 'freshies'.

Interviewer: Really, what does that mean 'freshies'? 
Taahira: They all come from Bangladesh. So they just come here, they don't know much English and stuff.

(Group interview)

Taahira also established a contrast between the food she ate at home with Western junk food'.

Taahira: And we do curries all the time.

Interviewer: Do you? That sounds nice.

Taahira: I hate curry, we eat it almost every single day.

Interviewer: Oh really, what would you like to eat then?

Taahira: Like chips and burgers.

Taahira: And like chicken wings

Interviewer: Do you like those? Do you get to eat them sometimes?

Taahira: Yeah, but there's not many like Halal.

(Individual interview)

Here Taahira stresses the contrast between Bangladeshi culture through the mention of food, religion, through the mention of Halal meat, and more Western youth values, through the mention of junk food, which she would like to be able to eat. This contrast between conflicting values sheds a new light on Taahira's 'punk' comment examined earlier. Her narrative shows a tension between her interest in youth culture and her family values which are more traditional, and construct youth culture as undesirable, as shown in Taahira's comment about being a bad pupil. Thus, her symbolic separation between public and private spheres can be interpreted not only as a way of articulating Otherness as part of her identity in a mainly monocultural school space, but also a way of articulating the tension between modernity (symbolised by youth culture) and tradition (symbolised by the expectations of her family).

\section{Marine and Taahira: fluid identities in multiple spaces}

Marine and Taahira experienced different national school contexts, underpinned by contrasting discourses of difference and approaches to inclusion in school. However, their identity narratives displayed similar forms of self-representations as pupils and similar ways of negotiating Otherness as part of their identities in school. These identity narratives built on a symbolic separation between different spaces and spheres: inside/outside, formal/informal, public/private. These symbolic separations allowed the girls to negotiate different forms of identity positioning in different spaces, by fitting in with the dominant, legitimate values of each space. In formal school spaces, which the girls tended to perceive as monocultural and monolingual (Welply, 2017), both girls emphasised the more impersonal, objective and learning-oriented dimensions of their perceived Otherness.

In the more informal spaces, they negotiated differences in accordance with peergroup culture and children's collective representations or social imaginaries. This articulation of cultural, religious and linguistic identity with formal school values and informal expectations of peer-group relations relied on a good understanding of the 
different values that were considered legitimate in different spheres (Bourdieu, 1991). This understanding allowed the two girls to negotiate Otherness in multiple ways as part of their identity narratives. These narratives were constructed across time, building on their trajectory as a pupil, past experiences, and future aspirations.

The girls' narratives were not devoid of contradictions and, as such, highlighted the fluid and changing dimensions of identity, in a dialectic between ipse and idem (Ricoeur, 1990). These contradictions reflected tensions experienced inside and outside school; tensions between Otherness and monocultural school ideologies; tensions associated with stereotyping and discrimination; and wider tensions which existed between tradition and modernity, all of which expressed the fear of a loss of identity in a process of acculturation to monocultural societies. However, whilst for Marine school represented a space in which she could overcome/reunify these tensions, for Taahira, school reflected the same lines of tension.

\section{Uncertainty and ambivalence around Otherness and belonging in school: Clara and Saalima}

In contrast to Marine and Taahira's narratives, those of Clara and Saalima were underpinned by uncertainty about school expectations and the place of 'differences' in school, which created feelings of unease and ambivalence around Otherness in their identities in school.

\section{Clara: uncertainty and unease}

Clara was a 10-year old girl born in France from parents who has emigrated from India as young adults. Her father ran a grocery store and her mother was a cleaner. Clara was the youngest of a family of five. In the classroom, her grades positioned her as an average student, with difficulties in literacy. Clara had a close friendship with her friend, Ophelie, but the two girls were at the periphery of peer-group relations in the classroom and, to some extent excluded, although Clara was quite liked by her peers.

Clara's identity narrative displayed uncertainty and unease about school expectations and about the place of 'differences' in school. As a result, she tended to adopt a 'default' position by keeping Otherness separate from school. This separation contributed to constructing an identity narrative which built on a distancing from France, and a strong identification with India, although there were contradictions and inconsistencies in her narrative of Otherness and belonging. She considered herself to be a struggling pupil, who did not always understand what the teacher expected from her. She was uncertain of what made a good pupil in school.

This uncertainty about defining herself as a pupil reflected Clara's lack of understanding of school expectations and values. She tended to refer to explicit values that were clearly voiced in the classroom (behave well, sit properly) rather than more implicit values such as learning, listening. This uncertainty about school values was also shown by her lack of understanding of the codes of the classroom, which in some cases meant she would get punished by the teacher without understanding why.

Clara's narratives showed that she had difficulties understanding the more implicit expectations and codes of the classroom. In Gumperz' terms, she lacked the 'contextualisation cues' to make sense of the classroom discourse and expectations (Gumperz, 1982; Gumperz \& Roberts, 1991). Consequently, she adopted a default position as a pupil, in which she attempted to stay out of trouble, and remained quiet in the classroom to avoid saying the wrong thing or being reprimanded like some of her peers. This highlights the role of children's 'repertoires' in their forms of identity constructions (Blommaert, 2005: 254; 2011).

The uncertainty and unease apparent in Clara's identity narrative was expressed also through her fear of speaking about India to teachers. She was very keen to speak to 
her friend about the way she felt attached to her Indian identity but was very unsure about speaking about it with teachers, fearing they might view her differently or fail her at school if she did so.

Clara: I don't really want to speak to the teachers about India... they might look at me differently... I don't know... maybe they fail me. Some teachers are racist, you know?

Clara's narrative clearly showed her uncertainty about the place of linguistic and cultural differences in school. Her interpretation of 'indifference to differences' in school appears to be translated into feelings of unease or even threat in relation to Otherness in formal school spaces. This shows her unclear understanding of the school ethos, which she attributes to teachers' personal attitudes, such as being racist, rather than to an overarching Republican approach to differences in school. Other comments show an attempt to make sense of the universalist principles promoted by French Republican school and the idea of "indifferences to differences".

Clara: for example, Kenny, he is not different from others, Kenny, he speaks French and he's a human, isn't' he. We are all humans; we are not different.

This comment shows how the "indifference to differences" principle is adapted to accommodate the domination of French language, which becomes the "normal", "standard" language and allows full inclusion of children in school (Welply, 2017).

It is not unusual for the fear of Otherness as illicit or negative to be associated with a view of French as the only legitimate language in school, constructing a hierarchy of desirable languages in school (Bourdieu, 1991; Welply, 2017). This confers a normalising symbolic power to French, the language of instruction, which comes to be misrecognised as such by all children. In contrast, other languages which fall outside of formal instruction are given a less legitimate and lower status. This was the case for Clara who felt that her speaking of Hindi was irrelevant as she could not speak it or write it. This absence of formal literacy in Hindi dispossessed the language of any legitimacy in the school sphere. She commented that nobody in school was interested in learning Hindi. Unlike Marine, she did not find a form of legitimisation of her other language in formal school spaces.

This led to Clara struggling to articulate differences with school values and as a result she constructed her perceived Otherness as entirely separate from formal school spaces. In the informal spaces of school, she was very intent on speaking about India with only her best friend but was reluctant to share with others because of the discrimination she faced in some cases.

Clara: sometimes they [other children] say to me "Hey, you're black!" For example, last year, there was girl Kholiane[ [...] who called me "bad Black" and I said "oh shut up, are you speaking to me? You hang out with Laossians. And she answered, "well at least we are not black like you".

Clara developed an identity narrative in which her Otherness was kept separate from the formal public school sphere. This strict separation and lack of bridges between the private and the public contrasts sharply with Marine and Taahira's ways of navigating different and sometimes conflicting values. In Clara's case, they might stem from a lack of clarity about school expectations, values and classroom codes, which reflected a misunderstanding of 'contextualisation cues' (Gumperz, 1982). This unease and ambivalence in Clara's identity narrative integrated both uncertainty about classroom 
codes and the implicit dimensions of the school discourse, with a tension around Otherness in the French school. This prevented Clara' from comfortably navigating the expectations of different school spaces and integrating school values with Otherness as part of her identity narrative. This separation was symbolised by an imaginary separation between India, the country she aspired to live in one day, and France, the country in which she depicted herself as living in only transiently yet wanted to feel she and her family had successfully integrated. This symbolic representation was underpinned by a tension between a transient migrant identity narrative and a narrative of integration and belonging to France.

\section{Saalima: uncertainty and ambivalence}

Saalima was an 11-year old girl of Bengali background, born in England. Her father was born in England and her mother had emigrated to England in her late teens to marry her father. Her father worked in a restaurant and her mother stayed at home. Saalima was the fifth child of a family of 7 . In the classroom, her grades positioned her as an average student, stronger in mathematics and with some difficulties in literacy. Saalima was close friends with Taahira (presented above) and another girl from Bangladeshi background, but she also spent time with other children, in particular the more popular Year 6 group of boys.

Saalima's narrative reflected similar uncertainties to Clara's in relation to school expectations and a difficulty in reconciling her understanding of school expectations and Otherness as part of her identity in school. Saalima defined herself as a pupil as 'one of those middle people, who needs help', who was 'noisy and chatty' in school yet 'quite quiet' at home. Her pupil identity narrative presented the image of a disobedient pupil:

Saalima: I hate the [school $]$ rules. I disobey the rules so much I get in trouble (Group interview)

This subversive positioning, however, was not just a straightforward rejection of school. Some of Saalima's comments pointed to a lack of understanding of school expectations and classroom codes. Her identity narrative also articulated negative feelings about unfair treatment throughout her school trajectory, that she was being 'picked on' and punished by teachers. This was confirmed by classroom observations, in which, prior to the interview, Saalima tended to be overdisciplined by the teacher.

(1) Saalima: I got my name moved every single day in year three. That's why I hated that year!

(Group interview)

(2) Saalima: I don't like Miss Reynolds, because she doesn't really explain much.

(Individual interview)

Saalima's identity narrative as a noisy and disobedient pupil, of middle ability, articulated representations that conflicted with the image of an 'ideal pupil' (Gillborn, 1995). However, this narrative did not just reflect a position of resistance against school but was underpinned by uncertainty about the codes and expectations in school. These contributed to her feeling of being picked on unfairly by teachers, without understanding what she was doing wrong. Like Clara's narrative, this highlighted the lack of understanding of more implicit expectations in the classroom and the absence of 'contextualisation cues' in Saalima's 'repertoire' (Gumperz, 1982; Blommaert, 2005). 
This uncertainty of expectations was reflected in Saalima's understanding of the place of other languages in formal school spaces, which she was not sure was allowed or not in school. Her comments showed that she felt English was the only legitimate language, but that there were not clear rules about language use in school (Welply, 2017). Saalima's uncertainty reflects the ambiguity of the school ethos itself, and the process of 'doublethink' (Blackledge, 2001b; Gillborn, 2008b) between a professed multilingual ethos and a more tacit monolingual ideology that is less inclusive of linguistic diversity. Saalima's view of the place of Otherness in school was at odds with the schools' approach to multilingualism and its ethos of inclusion. She commented that teachers were only interested in learning and literacy and not on children's personalities. This distinction between work and personal dimensions established a clear separation in Saalima's narrative. As such, she struggled to integrate Otherness as part of her identity narrative in formal school spaces, and to articulate school values within elements of Bangladeshi identity.

Saalima's identity narrative around her home culture and language was ambivalent and at times contradictory. During a group interview, Saalima's peers labelled her as non-English and trying to pretend she was English, which she did not contest openly, showing a process of legitimation and misrecognition in which dominant values of who belongs and who does not were constructed along monocultural norms by Saalima's peers (for further discussion see Welply, 2018). This was further reinforced in her individual interview where she explained she tried to speak less Bengali at school because her peers would make comments. After the group interview, she also asked to change the response she had given in a game under the section "my country" from Bangladesh to the town she lived in, and to changes her nationality from Bangladeshi to English.

The ambivalence expressed in Saalima's identity narrative reflects the tension between monolingual school spaces (both formal and informal) and her own Otherness. Her unclear understanding of school expectations meant she was unsure about what values were legitimised in specific fields, which made it difficult for her to find areas in which she could legitimise her own Otherness. This difficulty in reconciling aspects of Bengali identity with English identity was expressed in Saalima's narrative by distancing herself from Bangladesh and from Bengali, which she felt she could not speak very well. Saalima implicitly established a distinction, like Clara's above, between literacy in the dominant language of the school and the lack of literacy in their home language. However, whilst Clara simply mentioned that she could not read or write in Hindi, Saalima attempts to construct a more literate representation of Bengali, by drawing on her past experience of reading and writing in the language, thus conferring it a higher, more legitimate status on Bengali. Her narrative thus did not carry the same absolute idea of the dominant language of school as the sole literate language. This could be explained by the fact that Saalima attended Qur'anic school, and had a perception of other languages as literate, even if they were not part of the official school curriculum. Finally, Saalima's narrative also built on other representations of Otherness, such as wanting to live in Spain, the country of one of her friends. These future aspirations participated in constructing a cosmopolitan identity narrative, which transcended the dichotomy between her family's home country and England and, by extension, could be interpreted as a way to overcome the tensions between a monocultural school space and Otherness.

\section{Clara and Saalima: ambivalence and distancing}

Clara and Saalima's narratives presented similarities. They revealed a similar lack of understanding of the more implicit school expectations and classroom codes. Their narratives were underpinned by uncertainty: uncertainty about school values; uncertainty 
about how to relate to the teacher; and uncertainty about the place of Otherness in school and how to negotiate it as part of their identities.

This uncertainty made it more difficult for the girls to navigate different school spaces according to the more subtle and implicit expectations of each space. Consequently, both girls established a clear separation between formal monocultural school spaces and Otherness. This symbolic separation between formal school spaces and Otherness participated in ambivalent identity narratives associated with differences, underpinned by contradictions and inconsistencies. This ambivalence was illustrated in the girls' somewhat contradictory narratives about belonging, integration, language and nationality, which alternated between attachment towards and distancing themselves from Otherness in school.

In addition, the uncertainty displayed in the girls' identity narratives revealed misunderstanding of 'contextualisation cues' (Gumperz, 1982) and the gap between school and children's 'repertoires', which made it difficult for the girls to grasp the implicit school codes and expectations (Blommaert, 2005). It also showed how identity narratives concerning Otherness in school were not only developed in relation to Otherness itself or to school values but were also contingent on situational and contextual dimensions and different levels of understanding of more implicit codes and expectations in school.

The two girls' narratives reflected a tension between monoculturalism and Otherness in school. This tension can be understood as a tension between the idem dimensions of their identities, permanently constructed as dichotomous, whilst their attempt to overcome this tension reflects the ipse dimension, where more fluid positionings allowed them to construct different narratives of Otherness (Ricoeur, 1990). However, this dialectic was hard to articulate for the girls with their lack of understanding of implicit school expectations and limited their capacity to navigate different spaces according to different expectations.

The girls' different narratives about the place of Otherness in school operated a reversal of the official norms of each system. In the French republican context of 'indifference to differences', Clara feared that teachers would discriminate against her based on a personal Otherness. In addition, she articulated Otherness as central dimension of the close friendship she had with another non-immigrant girl. In contrast, in a context of multiculturalism, which acknowledged differences and celebrated diversity, Saalima maintained a clear distance between Otherness and school, in relation both to teachers and peers, unless it was in legitimate curriculum areas in the formal spaces of school. This highlights the limitations of official approaches to inclusion and differences for children who struggle to grasp the more implicit values in school.

\section{Discussion}

This article has shown that the four girls articulated Otherness through identity narratives that were fluid and multiple, caught in a dialectic between permanence (idem) and change (ipse) (Ricoeur, 1992) which, at times, were not devoid of tensions. However, within this complexity and multiplicity, some common threads can be identified across the girls' narratives, which can help us interrogate mechanisms of inclusion and exclusion at play in schools in different national contexts. These narratives highlighted the central role played by the girls' understanding (or lack thereof) of the more subtle and implicit school expectations and values in the way they articulated Otherness as part of their identity in school.

The four girls' narratives showed that the clearer their understanding of explicit and implicit school expectations, the more at ease they were in articulating Otherness as part of their identity in school, by adapting to different spaces according to the different perceived expectations for each space. This was the case for Marine and Taahira. Conversely, for Clara and Saalima, who did not have a clear understanding of school 
expectations, and did not grasp implicit norms and values, the tendency was to focus on the explicit, literal explanations which did not confer them the same ease in articulating Otherness across different school spaces. As a result, their narratives revealed was more of a separation between school and Otherness, whilst Marine and Taahira found bridges between school and Otherness, although they also experienced tensions between family, school and peer expectations.

What emerges from these narratives is that the ways in which the girls articulated Otherness as part of their identity in school had less to do with the approaches to inclusion promoted in the English and French school (which stood in sharp contrast from one another), but more to do with their understanding of the unspoken expectations and legitimate values of different school spaces. The four girls interpreted and translated the schools' discourses of inclusion in different ways, building on their own cultural, linguistic and social repertoires to construct multiple and changing identity narratives. These narratives articulated the girls' understanding of (at times conflicting) school expectations and values with wider experiences of Otherness within and outside school. They provide valuable insights into the ways approaches to inclusion in different national educational contexts might or might not impact on the experience of children from immigrant-background, and the different ways in which children might interpret and negotiate these understandings of inclusion.

The narratives presented in this article show how children often experienced a range of (sometimes) conflicting values, norms and expectations related to inclusion in school and in the classroom. In these fluid contexts, children's grasp of contextualisation cues (Gumperz, 1982) and repertoires (Blommaert, 2005) played a significant role in the way the girls felt their Otherness could be included as part of their identities in school. Processes of legitimation and misrecognition created hierarchies of Otherness which at times ran counter to the inclusive ethos of the school (Bourdieu, 1991). In the French school, Clara reinterpreted the idea of "indifference to differences" as a normalisation of Frenchness at the exclusion of other languages symbolically positioned as inferior. In the English school, Saalima performed a similar misrecognition of the school's ethos of inclusion in her narrative, which led her to distance herself from her Bengali identity in school. The girls thus experienced different levels of inclusion across the schools, which were less dependent on the philosophies of inclusion in each national context, than on the girls' capacity to understand the unspoken expectations in each setting.

There were, however, differences in the "functions of inclusion" between the French and English schools. First, in the French school, the model of inclusion was explicit, with meant that most children understood the "indifference to differences" principle. Second, the clear separation between formal and informal spaces helped to clearly distinguish separate conceptions of Otherness within each space (classroom, peer groups). Whilst Otherness was excluded from formal school spaces, it was given a high status amongst peers in informal school spaces. This meant that children had multiple opportunities for inclusion, which allowed them to develop their own "language of difference" in the absence of any official forum for speaking about differences. This was the case for Marine, for whom school offered a space in which she could transcend the tension between what she perceived as Hmong tradition and the French universalist and secular school principles.

Conversely, in the English school, there was a discrepancy between the stated inclusive school ethos, symbolised by multilingual signs and religious celebrations, and the more tacit monocultural school practices. This made it more difficult for children to navigate expectations across different school spaces. Whilst the expected outcome of this inclusive multicultural and multilingual environment would be that children felt their Otherness could be integrated within their identity at school, the girls' narratives tended to point to the opposite. The lack of clear separation between formal and informal spaces, 
and the reliance on unspoken expectations and practices meant that the uncertainty and contradictions surrounding the place of Otherness in school permeated all areas of children's school experience. Even when children such as Taahira possessed the right contextualisation cues and repertoires (Gumperz, 1982, Blommaert, 2005), they struggled to reconcile the tension between a professed mode of inclusion and more implicit modes of exclusion. This is shown in Saalima's attempt to distance herself from a Bengali identity in front of peers, and in Taahira's feeling that a good pupil did not include the "wrong" values.

Finally, although there was not sufficient space in this article to explore this in more depth, it is important to acknowledge that the negotiation of identities and experiences in school did not take place in a vacuum, but were located within wider contexts: family, community, neighbourhood. The girls' narratives show the role played by family values and peer group cultures on their experiences and the construction of their identities. The local urban area also impacted on a sense of place and belonging. In the French school, children from immigrant and non-immigrant backgrounds lived near each other, many in tower blocks, which gave them a sense of common belonging. In contrast, in the English school, children lived in separate areas. Taahira and Saalima lived in close proximity to each other and other Bangladeshi family but commented that because they did not live near any other of their peers, it would be strange to see them outside of school. This created different imaginaries of belonging, inscribed within the geographies of their day-to-day experience. Within this, youth culture, in different forms, played a role in the girls' experiences, whether it was through reference to break dancing, punk culture, graffiti, or contemporary music.

\section{Conclusion}

This article shows that there is a need to look beyond broad models of inclusion at a national, policy or institutional level to understand the everyday experiences of inclusion of children from immigrant backgrounds. It highlights how children's experiences of belonging and inclusion at school reflect wider relationships between school and society, which will vary across national and local contexts, but are also the result of specific institutional structures, practices, values and children's understanding of the more implicit expectations of school. It highlights the need to look at school as an ensemble of multiple spaces, which often hold different expectations, norms and values, both explicit and implicit. It also draws attention to the limitations of approaches to inclusion in schools, and the discrepancy between a professed inclusive ethos and actual inclusive outcomes.

Despite different conceptual constructions of inclusion and difference in the French and English schools, all four girls understood their schools to be fundamentally monolingual and monocultural. However, for those girls who had a good grasp of implicit expectations (Marine and Taahira), it was easier to develop strategies that allowed them to feel included within their Otherness in formal school spaces and with peers. For those girls who did not grasp these expectations, this was more difficult and they tended to try to downplay their Otherness in different school spaces, for fear of not being included, either by teachers (as in the case of Clara) or by peers (as is the case for Saalima). Understanding these mechanisms of inclusion and exclusion, and how children interpret them beyond the stated school values and practices, can help reflect on the specific and multiple needs of children from immigrant backgrounds and the best ways in which schools can respond to them by promoting inclusive change.

\section{Note}

This article draws on a wider ethnographic study which will be published as a book. Welply, O. (forthcoming) Immigration, Integration and Education: Perspectives of 
Children of Immigrants in France and England. London: Routledge. Other aspects of the four girls' narratives have been examined elsewhere (see Welply, 2015; 2017; 2018; 2019).

\section{References}

Alexander, R. (2000). Culture and Pedagogy: International Comparisons in Primary Education. Oxford: Blackwell.

Armstrong, F., Armstrong, D., \& Barton, L. (2016). Inclusive education: policy, contexts and comparative perspectives. London: Routledge.

Aikman, S., \& Dyer, C. (2012). Education and Inclusion: Re-Examining the Narratives. Compare: A Journal of Comparative and International Education, 42(2), 177-185.

Blommaert, J. (2005). Discourse: A critical introduction. Cambridge University Press.

Bourdieu, P. (1991). Language and Symbolic Power. Cambridge: Polity Press.

Cusset, P.-Y., Garner, H., Harfi, M., Laine, F., \& Marguerit, D. (2015). Young People from Immigrant Backgrounds: What Are the Barriers to Their Economic Integration? Paris: France Stratégie.

Delamotte, R., Penloup, M.-C., \& Reuter, Y. (2016). Décrocher/Raccrocher à l'école : la part du français. Repères. Recherche en didactique du français langue maternelle. (53), 7-12.

Fukuda-Parr, S. (2016) From the Millennium Development Goals to the

Sustainable Development Goals: shifts in purpose, concept, and politics of global goal setting. Gender \& Development, 24(1), 43-52.

Gillborn, D. (2010) The colour of numbers: surveys, statistics and deficit-thinking about race and class. Journal of Education Policy, 25(2), 253-276.

Gillborn, D. (2015). Intersectionality, Critical Race Theory, and the Primacy of Racism: Race, Class, Gender, and Disability in Education. Qualitative Inquiry, 2 1(3), 277287.

Gosh, R., \& Galczynski, M. (Eds.). (2014). Redefining Multicultural Education: Inclusion and the Right to Be Different. Toronto: Canadian Scholar's Press.

Groundwater-Smith, S., Dockett, S., and Bottrell, D., eds. (2015). Participatory Research with Children and Young People. London: SAGE.

Gumperz, J. J. (1982). Discourse strategies (Vol. 1). Cambridge University Press.

Hutchinson, J. (2018). Educational Outcomes of Children with English as an Additional Language. Cambridge: Bell Foundation.

Kearney, R. (2004). On Paul Ricoeur: The Owl of Minerva. Aldershot: Ashgate.

Liu, Y., Fisher, L., Forbes, K., \& Evans, M. (2017). The Knowledge Base of Teaching in Linguistically Diverse Contexts: 10 Grounded Principles of Multilingual Classroom Pedagogy for EAL. Language and Intercultural Communication, 17(4), 378-395.

Lorcerie, F. (2011). École et Ethnicité en France : Pour une Approche Systémique Contextualisée SociologieS [En ligne]. URL : http://sociologies.revues.org/3706

Meetoo, V. (2019) Beyond 'between two cultures': micro processes of racialised and gendered positioning of South Asian and Muslim girls in an 'everyday' British multicultural school context, Gender and Education. Published online: DOI: 10.1080/09540253.2019.1632810

Miles, S., \& Singal, N. (2010). The Education for All and Inclusive Education Debate: Conflict, Contradiction or Opportunity? International Journal of Inclusive Education, 14(1), 1-15.

Mintz, J., \& Wyse, D. (2015). Inclusive pedagogy and knowledge in special education: addressing the tension. International Journal of Inclusive Education, 19(11), 11611171. 
Mirza, H. S. (2015). Dangerous Muslim Girls? Race, Gender and Islamophobia in British Schools. The Runnymede School Report: Race, Education and Inequality in Contemporary Britain, 40-43.

Morgan, N. (2015). Nicky Morgan: Why knowledge matters. London: Carlton Club. Retrieved from https://www.gov.uk/government/speeches/nicky-morgan-whyknowledge-matters

Plaisance, É. \& Schneider, C. (2013). L'inclusion scolaire des enfants handicapés comme révélateur des tensions éducatives. Phronesis, 2(2-3), 87-96. https://doi.org/10.7202/1018076ar

Raveaud, M. (2006). De l'enfant au citoyen : la construction de la citoyenneté à l'école en France et en Angleterre. Paris: Presses universitaires de France.

Raveaud, M. (2008). Culture-Blind? Parental Discourse on Religion, Ethnicty and Secularism in the French Educational Context. European Educational Research Journal, 7(1), 74-88.

Ricoeur, P. (1992). Oneself as Another. Chicago: University of Chicago Press.

Shain, F. (2012). "Intersections of "Race", Class and Gender in the Social and Political Identifications of Young Muslims in England." In K. Bhopal and J. Preston, (Eds.), Intersectionality and "Race" in Education, 138-157. Abingdon: Routledge.

Slee, R. (2009). The Inclusion Paradox: The Cultural Politics of Difference. In M. Apple, W. Au \& L. A. Gandin (Eds.), The Routledge International Handbook of Critical Education. New York: Routledge. Pp 177-189

Strauss, A. L., \& Corbin, J. M. (1998). Basics of Qualitative Research: Techniques and Procedures for Developing Grounded Theory (2nd ed.). Thousand Oaks, CA: Sage.

Tomlinson, S. (2015). Is a sociology of special and inclusive education possible? Educational Review, 67(3), 273-281.

Toubon, J., \& Avenard, G (2018) De la naissance à six ans : au commencement des droits. Paris : Défenseur des Droits

Unterhalter, E. (2014) Measuring Education for the Millennium Development Goals: Reflections on Targets, Indicators, and a Post-2015 Framework, Journal of Human Development and Capabilities, 15 (2-3), 176-187, doi: $10.1080 / 19452829.2014 .880673$

Vertovec, S. (2017). Talking around Super-Diversity. Ethnic and Racial Studies, Published online 5th December 2017. Retrieved 18th of June 2018. URL: https://doi.org/10.1080/01419870.2017.1406128.

Warmington, P., Gillborn, D., Rollock, N., \& Demack, S. (2018). “They Can’t Handle the Race Agenda”: Stakeholders' Reflections on Race and Education Policy, 19932013. Educational Review, 70(2018), 409-426.

Welply, O. (2015). Re-imagining Otherness: An exploration of the global imaginaries of children from immigrant backgrounds in primary schools in France and England. European Educational Research Journal, 14(5): 430-453.

Welply, O. (2017). 'My language ... I don't know how to talk about it' children's views on language diversity in primary schools in France and England. Language and Intercultural Communication, 17(4): 437-454.

Welply, O. (2018). 'I'm not being offensive but...' intersecting discourses of discrimination towards Muslim children in school. Race Ethnicity and Education, 21(3): 370-389.

Welply, O. (2019). A crisis in education? An Arendtian perspective on citizenship and belonging in France and England. British Journal of Sociology of Education, 4O(6): $759-775$. 


\begin{abstract}
About the Author
Oakleigh Welply is an Associate Professor at the School of Education, Durham University. She received her PhD in Sociology of Education from the University of Cambridge. Her main areas of research and teaching include social theory; the relationship of education to issues of language, religion, globalisation and citizenship; national policies of integration and youth identities; immigration and education in France and England; the development of cross-national methodologies for research with diverse communities in European countries and global citizenship education. Theoretically, her work is mainly inspired by the works of Paul Ricoeur, Hannah Arendt, and Pierre Bourdieu to investigate the intersection between wider structures and the subjectivities of young immigrants' identities and experiences.
\end{abstract}

